\title{
POPULASI MONYET EKOR PANJANG (Macaca fascicularis) DI HUTAN LINDUNG DESA PULAU JAYA KECAMATAN TEMPUNAK KABUPATEN SINTANG
}

(The Population Of Long-tailed Macaques (Macaca fascicularis) in Protected Forest Pulau Jaya Village, Tempunak Sub-district, Sintang Regency)

\section{Heriditus Sangkauw, Hari Prayogo, M. SofwanAnwari,}

Fakultas Kehutanan Universitas Tanjungpura Pontianak. J1. Daya Nasional Pontianak 78124 E-mail: heriditussangkau22@gmail.com

\begin{abstract}
Protected Forest Areas in Pulau Jaya Village still have shifting cultivation activities. The shifting cultivation system that used has caused forest damage ecosystem which is habitat of long-tailed macaque.The study aim to determined the population and density of long-tailed macaque in Pulau Jaya Village, Tempunak sub-district, Sintang regency. The research on population of Long-tailed macaque was conducted four-month period strarted from february to june 2018. The survey was conduct by using track, there is five track that conducted survey. It was also conducted repeated three times surveys on 1000 meter length track. The result of this research shown that the total number of this long-tailed macaque is about 114 individu and 13 groups while the individual density is 0,0676 to 1,86 individu per hectare and the group density is 0,0806 to 0,2086 group per hectare.
\end{abstract}

Keywords : Macaca fascicularis, Population, Pulau jaya village, secondary forest.

\section{PENDAHULUAN}

Monyet Ekor Panjang termasuk dalam ordo primata famili cercopithecidae, ciri primata antara lain memiliki lima jari, bentuk gigi yang sama, memiliki kuku jari. Primata didunia terdapat sekitar 195 jenis primata, dari jumlah tersebut 40 jenis diantaranya terdapat di Indonesia, dan 24 diantaranya merupakan jenis endemik, dalam klasifikasinya 40 jenis primata tersebut dikelompokan ke dalam 5 suku dan 9 marga (Supriatna dan Wahyono, 2000). Satwa primata memiliki fungsi utama sebagai penyebar biji dan menjaga keseimbangan ekosistem (Basalamah, 2010).

Monyet ekor panjang merupakan salah satu primata yang hidup liar di hutan Kalimantan, yang tersebar luas secara acak di Asia Tenggara. Monyet ekor panjang ditemukan di berbagai lingkungan dengan kelimpahan terbesar di hutan rawa dan hutan sekunder (Fooden 1995 dalam Malaivijitnond \& Hamada 2008). Monyet ekor panjang juga umumnya ditemukan di tepi sungai sekitar hutan karena spesies ini mencari perlindungan pada waktu malam hari di sepanjang sungai. Monyet merupakan satwa yang memiliki kemampuan beradaptasi yang sangat tinggi terhadap lingkungan sehingga mampu hidup di berbagai tempat. Kehidupan monyet memiliki nilai yang cukup tinggi bagi manusia seperti nilai ekologi, rekreasi dan komersial (Djuantoko, 2008).Satwa ini juga dapat memberikan manfaat 
yang tidak kecil dalam bidang pariwisata (Shackley,1996; Newsome et al., 2005; Djuantoko, 2008).

Hutan di Dusun Seranjuk Desa Pulau Jaya merupakan kawasan yang dipergunakan masyarakat untuk berladang, dengan pola ladang berpindah. Kegiatan ladang berpindah yang dilakukan oleh masyarakat suku dayak di kawasan sedikit demi sedikit telah merusak hutan yang selama ini menjadi habitat monyet. Pengurangan luas areal hutan yang terjadi menyebabkan primata ini mencari makan pada ladang masyarakat yang berada di sekitar hutan. Monyet ekor panjang di kawasan ini sering menjadi hewan buruan oleh masyarakat untuk dikonsumsi dagingnya. Perburuan ini sudah terjadi sejak lama. Kini populasi primata ini menjadi terancam akibat perburuan yang dilakukan masyarakat suku dayak di kawasan hutan tersebut. Perburuan oleh masyarakat memang tidak dapat dihindari namun disisi lain satwa ini tidak boleh punah.Penelitian ini bertujuan untuk mendapatkan data populasi dan kepadatan monyet ekor panjang di kawasan hutan lindung sekitar Dusun Seranjuk Desa Pulau Jaya Kecamatan Tempunak Kabupaten Sintang.

\section{METODE PENELITIAN}

Penelitian ini dilakukan di kawasan hutan sekunder Desa Pulau Jaya Kecamatan Tempunak Kabupaten Sintang, penelitian dilakukan sebanyak dua kali pengambilan data, pengambilan data pertama dimulai tanggal 7 - 16
Februari 2018 kemudian dilanjutkan pada tanggal 29 Mei - 15 Juni 2018.

Pelaksanaan penelitian ini pengumpulan data dikelompokan atas data primer dan data sekunder. Data primer diperoleh langsung di lokasi penelitian yang berupa data jumlah individu dan jumlah kelompok populasi monyet ekor panjang yang ditemukan pada jalur pengamatan.Data sekunder diperoleh dari berbagai sumber yang meliputi data tentang keadaan umum lokasi penelitian dan studi literatur.

Penentuan Lokasi Penelitian

Pelaksanaan penelitian dimulai dengan melakukan orientasi lapangan terlebih dahulu untuk mendapatkan lokasi yang tepat. Hal ini penting dalam rangka peletakan jalur penelitian agar berada pada lokasi penelitian yang diyakini sebagai habitat maupun persebaran monyet. Pengumpulan data populasi diperoleh dengan melakukan pengamatan langsung menggunakan metode jalur transek (line transect).

Penentuan Jalur Pengamatan

Penentuan jalur pengamatan dilakukan secara purposive, jarak antar jalur 500 meter. Lebar jalur pengamatan adalah 60 meter dengan 30 meter ke kiri dan 30 meter ke kanan. Jumlah jalur pengamatan sebanyak 5 buah dengan panjang jalur 1000 meter. Panjang areal yang dilakukan pengamatan sekitar 3000 meter.

\section{Pengamatan Populasi}

Pengamatan dilakukan setiap hari, dalam satu jalur dilakukan tiga kali ulangan, waktu pengamatan dilakukan pada pagi dan sore hari. Selama waktu 
tersebut dicatat jumlah individu dan jumlah kelompok populasi monyet yang terlihat. Setiap jalur dilakukan pengulangan pengamatan sebanyak 3 kali ulangan.

Analisis Data

Data yang telah didapatkan dimasukan ke dalam tabel dan dihitung jumlah individu dan jumlah kelompok populasi.

Varians $\quad: S^{2}=\frac{\sum(x i-\bar{x})^{2}}{(n-1)}$

Simpangan baku $: S e=\sqrt{\frac{S^{2}}{n}}$

Dimana:

$\mathrm{Se}=$ Standar error

$\mathrm{S}^{2}=$ Varians

$\mathrm{n}=$ Jumlah jalur pengamatan

Kepadatan Individu :

$$
\mathrm{KI}=\overline{\boldsymbol{x}} \pm \mathbf{t} \alpha . \mathrm{Se}
$$

Dengan selang kepercayaan $95 \%$

Dimana :

$\mathrm{KI}=$ Kepadatan individu

$\bar{x}=$ Nilai rata-rata seluruh jalur/ha (individu atau kelompok)

$x i=$ Jumlah individu atau kelompok

jalur ke-1 sampai dengan $\mathrm{i}$

$\mathrm{n}=$ Jumlah jalur pengamatan

$\mathrm{Sd}=$ Standar deviasi

2. Kepadatan Kelompok (KK)

$$
\mathrm{KK}=\overline{\boldsymbol{x}} \pm \mathbf{t} \alpha . \mathrm{Se}
$$

Untuk menduga selang kepadatan Individu/Ha dan kepadatan Kelompok/Ha digunakan rumus sebagai berikut :

1. Kepadatan Individu

Nilai tengah sampel dihitung dengan rumus :

$$
\bar{x}=\frac{\sum x i}{n}
$$

Varians dihitung dengan rumus (Sugiyono 2017) :

Dengan selang kepercayaan $95 \%$

3. Jumlah Individu (JI)

$\mathrm{JI}=\mathrm{KI} \times$ Luas areal penlitian

Dengan selang kepercayaan $95 \%$

$$
\mathbf{J I}=(\mathbf{m}, \mathbf{n})
$$

Dimana :

$\mathrm{m}=$ Jumlah individu terendah

$\mathrm{n}=$ Jumlah individu tertinggi

4. Jumlah Kelompok

$\mathrm{JK}=\mathrm{KK} \mathrm{x}$ Luas areal penlitian

Dengan selang kepercayaan $95 \%$

$$
\mathbf{J K}=(\mathbf{o , p})
$$

Dimana :

$\mathrm{o}=$ Jumlah individu terendah

$\mathrm{p}=$ Jumlah individu tertinggi

\section{HASIL DAN PEMBAHASAN}

Hasil pengamatan kepadatan individu per hektar dalam tiga kali ulangan untuk masing-masing jalur pengamatan dengan selang kepercayaan 95\% dapat dilihat pada tabel berikut : 
Tabel 1. Pendugaan Kepadatan Individu Per ha (Estimated Individual Density of Long-tailed Macaques per Hectare)

\begin{tabular}{ccccc}
\hline $\begin{array}{c}\text { No } \\
\text { Jalur }\end{array}$ & $\begin{array}{c}\text { Luas } \\
\text { Jalur }\end{array}$ & $\begin{array}{c}\text { Jumlah } \\
\text { Individu }\end{array}$ & $\begin{array}{c}\text { Kepadatan } \\
\text { Individu per } \\
\text { Ha }\end{array}$ & $\begin{array}{c}\text { Kepadatan Individu Per Ha } \\
\text { SK 95\% }\end{array}$ \\
\hline 1 & $6 \mathrm{Ha}$ & 8,33 & 1,39 & $0,676-1,86$ \\
2 & $6 \mathrm{Ha}$ & 10,66 & 1,78 & \\
3 & $6 \mathrm{Ha}$ & 9,66 & 1,62 & \\
4 & $6 \mathrm{Ha}$ & 5,33 & 0,89 & \\
5 & $6 \mathrm{Ha}$ & 4 & 0,67 & \\
\hline
\end{tabular}

a. Kepadatan individu/ha selang kepercayaan $95 \%$ adalah :

$$
\begin{aligned}
\mathrm{KI}_{1} & =\bar{x} \pm \mathrm{t}(\alpha / 2) . S e \\
& =1,268-2,776 \times 0,213 \\
& =1,268-0,592 \\
& =0,676 \\
\mathrm{KI}_{2} & =\bar{x} \pm \mathrm{t}(\alpha / 2) . S e \\
& =1,268+2,776 \times 0,213 \\
& =1,268+0,592
\end{aligned}
$$

Jadi kepadatan individu monyet/ha dengan selang kepercayaan 95\% terletak antara 0,676 ekor/ha - 1,86 ekor/ha.

Berdasarkan analisis data kepadatan kelompok per hektar dalam tiga kali ulangan untuk masing-masing jalur pengamatan dengan selang kepercayaan 95\% dapat dilihat pada tabel 2 :

Tabel 2. Pendugaan Kepadatan Kelompok Per ha(Estimated Group Density of Long-tailed Macaques per Hectare)

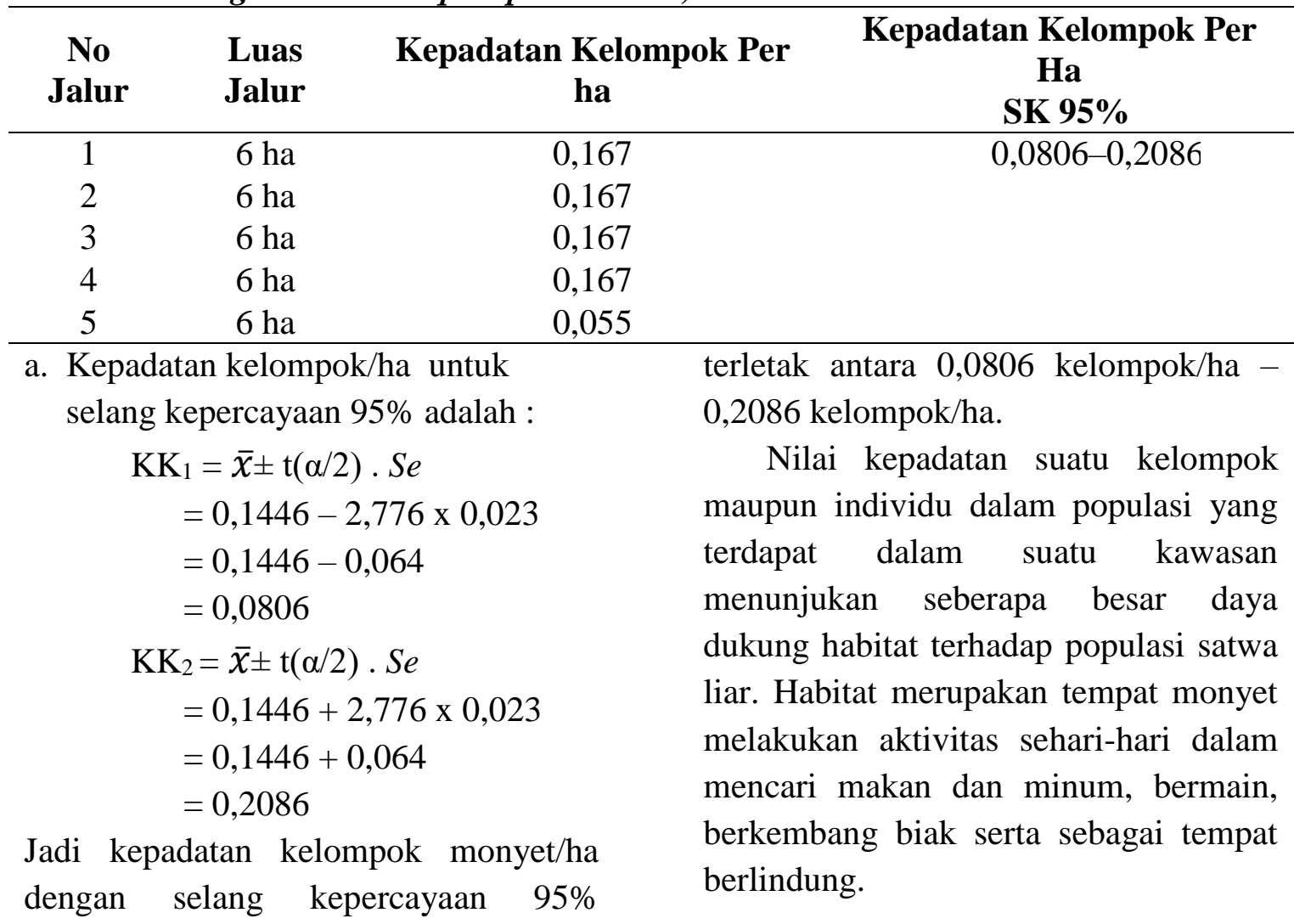


Nilai kepadatan tersebut ditunjukan dalam angka, semakin tinggi nilai kepadatan maka semakin tinggi pula tingkat daya dukung habitatnya. Berdasarkan hasil analisa data yang diperoleh dalam penelitian, pada selang kepercayaan 95\% kepadatan individu monyet ekor panjang pada kawasan hutan sekunder Desa Pulau Jaya Dusun Seranjuk terletak antara 0,676 ekor/ha 1,86 ekor/ha dengan kepadatan kelompok antara 0,0806 kelompok/ha 0,2086 kelompok/ha. Nilai kepadatan individu maupun kepadatan kelompok monyet ekor panjang di Desa Pulau Jaya ini lebih rendah jika dibandingkan dengan kepadatan individu dan kelompok di Desa Sungai Bemban dalam Kawasan Gunung Ambawang Kecamatan Kubu Kabupaten Pontianak, dimana pada kawasan tersebut kepadatan individunya terletak antara 1,6973 ekor/Ha hingga 3,0367 ekor/Ha pada selang kepercayaan $95 \%$.
Sedangkan kepadatan kelompok terletak antara 0,2158 kelompok/Ha hingga 0,4502 kelompok/Ha.

Kepadatan individu maupun kelompok berbeda antara satu daerah dengan daerah lainnya. Perbedaan tersebut disebabkan oleh kondisi daya dukung yang berbeda-beda pada setiap kawasannya. Kawasan hutan sekunder Desa Pulau Jaya kepadatan individu dan kelompok monyet tidak tersebar secara merata pada setiap jalur pengamatan, individu maupun kelompok monyet lebih banyak dijumpai pada kondisi hutan yang terdapat banyak pepohonan terutama pada daerah yang terdapat buah-buahan atau makanan lainnya, sementara kurang banyak ditemukan pada daerah permudaan (bekas ladang).

Rerata jumlah individu untuk masing-masing jalur pengamatan serta jumlah individu pada lokasi penelitian pada masing-masing selang kepercayaan dapat dilihat pada tabel 3 :

Tabel 3. Pendugaan Jumlah Individu Monyet Ekor Panjang Per ha (Estimated Individual Number of Long-tailed Macaques per Hectare)

\begin{tabular}{cccc}
\hline $\begin{array}{c}\text { No } \\
\text { Jalur }\end{array}$ & $\begin{array}{c}\text { Luas } \\
\text { Jalur }\end{array}$ & $\begin{array}{c}\text { Jumlah Individu Per } \\
\text { ha }\end{array}$ & $\begin{array}{c}\text { Jumlah Individu Pada Lokasi } \\
\text { Penelitian } \\
\text { SK 95\% }\end{array}$ \\
\hline 1 & 6 ha & 8.33 & $21-56$ \\
2 & 6 ha & 10.66 & \\
3 & 6 ha & 9.66 & \\
4 & 6 ha & 5.33 & \\
5 & 6 ha & 4 & selang kepercayaan 95\% dapat dilihat \\
\hline \multicolumn{7}{c}{ Analisa } & data jumlah kelompok & pada tabel 4 : \\
dapat dilihat pada lampiran 6 diperoleh &
\end{tabular}

rerata jumlah kelompok untuk masingmasing jalur pengamatan serta jumlah kelompok pada lokasi penelitian untuk 
Tabel 4. Pendugaan Jumlah Kelompok Monyet Ekor Panjang Per ha (Estimated Group Number of Long-tailed Macaques per Hectare)

\begin{tabular}{|c|c|c|}
\hline $\begin{array}{l}\text { No } \\
\text { Jalur }\end{array}$ & $\begin{array}{c}\text { Jumlah Kelompok } \\
\text { Per ha }\end{array}$ & $\begin{array}{c}\text { Jumlah kelompok Pada Lokasi } \\
\text { Penelitian } \\
\text { SK 95\% } \\
\end{array}$ \\
\hline 1 & $6 \mathrm{ha}$ & $3-7$ \\
\hline 2 & 1.00 & \\
\hline 3 & 1.00 & \\
\hline 4 & 1.00 & \\
\hline 5 & 0.33 & \\
\hline \multicolumn{3}{|c|}{ Keberadaan monyet ini juga } \\
\hline menunj & n bahwa mereka mampu & dengan jumlah kelompok 3 hingga 7 \\
\hline \multicolumn{2}{|c|}{$\begin{array}{l}\text { menunjukan bahwa mereka mampu } \\
\text { bertahan hidup dengan daya dukung }\end{array}$} & $\begin{array}{l}\text { kelompok. Jumlah individu maupun } \\
\text { kelompok yang ditemukan di Desa }\end{array}$ \\
\hline $\begin{array}{l}\text { menyed } \\
\text { bagi be }\end{array}$ & $\begin{array}{l}\text { an banyak sumber pakan } \\
\text { gai jenis satwa liar termasuk }\end{array}$ & $\begin{array}{l}\text { Pulau Jaya lebih kecil apabila } \\
\text { dibandingkan dengan penelitian }\end{array}$ \\
\hline \multirow{2}{*}{\multicolumn{2}{|c|}{$\begin{array}{l}\text { monyet. Pengamatan secara langsung, } \\
\text { terdapat beberapa kesulitan yang }\end{array}$}} & populasi monyet yang dilakukan di \\
\hline & & Desa Sungai Bemban Kecamatan Kubu \\
\hline \multicolumn{2}{|c|}{$\begin{array}{l}\text { dialami seperti masalah topografi dan } \\
\text { sifat-sifat yang menonjol dari satwa ini. }\end{array}$} & $\begin{array}{l}\text { Kabupaten Pontianak, di kawasan ini } \\
\text { jumlah individu pada areal penelitian }\end{array}$ \\
\hline \multirow{2}{*}{\multicolumn{2}{|c|}{$\begin{array}{l}\text { Monyet ekor panjang sangat sensitif } \\
\text { dengan kehadiran manusia sehingga }\end{array}$}} & dengan selang kepercayaan $95 \%$ \\
\hline & & berkisar antara 51 hingga 92 ekor \\
\hline $\begin{array}{l}\text { ketika } \\
\text { satwa }\end{array}$ & $\begin{array}{l}\text { yadari kehadiran manusia, } \\
\text { kan lari menjauhi manusia }\end{array}$ & $\begin{array}{l}\text { dengan jumlah kelompok berkisar } \\
\text { antara } 7 \text { hingga } 14 \text { kelompok. }\end{array}$ \\
\hline
\end{tabular}
ataupun berdiam diri pada pohon yang sangat tinggi, jika hal ini terjadi maka akan sangat sulit untuk melakukan perhitungan.

Jumlah individu monyet ekor panjang pada penelitian ini dalam satu kelompok berkisar antara 4 sampai 13 ekor. Menurut Supriatna dan Wahyono (2000) jumlah individu dalam kelompok dapat mencapai 20-30 ekor. Kecilnya jumlah individu yang ditemukan mungkin disebabkan oleh perburuan yang dilakukan masyarakat lokal terhadap satwa ini.

Berdasarkan hasil penelitian pada selang kepercayaan $95 \%$ diperoleh jumlah individu pada areal penelitian

\section{KESIMPULAN}

Jumlah individu monyet ekor panjang (Macaca fascicularis) di kawasan Hutan Sekunder Desa Pulau Jaya Dusun Seranjuk pada selang kepercayaan $95 \%$ terletak antara 21ekor/ha hingga 56 ekor/ha dengan jumlah kelompok terletak antara 3 kelompok/ha hingga 7 kelompok/ha.

Kepadatan individu monyet ekor panjang (Macaca fascicularis) di kawasan Hutan Sekunder Desa Pulau Jaya Dusun Seranjuk pada selang kepercayaan $95 \%$ terletak antara 0,676 ekor/ha hingga 1,86 ekor/ha dengan kepadatan kelompok antara 0,0806 
JURNAL HUTAN LESTARI (2019)

Vol. 7 (1) : 578 - 584

kelompok/ha hingga $\quad 0,2086$

kelompok/ha.

\section{DAFTAR PUSTAKA}

Basalamah F, A Zulfa, D Suprobowati, D Astriana, Susilowati, A Anggraeni, dan R Nurul. 2010. Status Populasi Satwa Primata di Taman Nasional Gunung Gede Pangrango dan Taman Nasional Halimun Salak Jawa barat. Jurnal Primatologi Indonesia. 7(2):5559.

Djuantoko, Retno NU, dan Wiyono. 2008. Perilaku Agresif Monyet Macaca fascicularis (Raffles 1821) Terhadap Wisatawan di Hutan Wisata Alam Kaliurang Yogyakarta. Jurnal Biodiversitas. 9(4): 301-305.

Malaivijitnond S, and Hamada Y. 2008. Current Situation and Status of Long-tailed Macaques (Macaca fascicularis) in Thailand. The Natural History Journal of Chulalongkorn University. 8(2):185-204.

Supriatna J, dan Edy HW. 2000. Panduan Lapangan Primata Indonesia. Yayasan Obor Indonesia. 